\title{
Inter-Regional Differences in Travel Time to the Nearest Nursery for Children with Mild Acute Illness in Japan
}

\author{
Akira Ehara ${ }^{1}$ \\ ${ }^{1}$ Faculty of Health Services Management, Hiroshima International University, Hiroshima, Hiroshima, Japan
}

\begin{abstract}
Access to day-care services for children with mild acute illness is important for working parents, because infants and toddlers often suddenly become ill, and most Japanese nursery schools do not accept children with even mild illnesses. Actual travel time to nurseries providing such day-care services is one of the indicators for measuring accessibility. However, this variable has not been well analyzed in previous work. To clarify practical access to such nurseries, this study used a car navigation algorithm to calculate the percentage of the population of children in Japan who can access nurseries providing services for children with mild acute illnesses within 15 to 30 minutes and compared this with the proportion of children living within a linear distance of $10 \mathrm{~km}$ of such nurseries. Of the 4,987,706 children younger than 5 years in $2015,51.7 \%$ lived in areas from which the nearest nursery for children with mild acute illness was accessible within 0-15 minutes by automobile. In addition, $81.5 \%$ lived within 0-30 minutes of such nurseries, and the same percentage (81.5\%) lived within a linear distance of $10 \mathrm{~km}$ of such nurseries. Both calculation methods (travel time and linear distance) showed inter-regional differences in accessibility, and the proportion of children with access to these nurseries was higher in heavily populated regions (e.g., Kanto and Kinki) than in less populated regions (e.g., Hokkaido and Tohoku). Children and caregivers throughout Japan should have equal access to these nurseries, because the national government subsidizes such services.
\end{abstract}

Keywords: child care; geographical information systems; Japan; nurseries for children with mild acute illness; social environment

Tohoku J. Exp. Med., 2018 July, 245 (3), 153-158. C 2018 Tohoku University Medical Press

\section{Introduction}

In Japan, $90.0 \%$ of men and $72.1 \%$ of women aged 25-34 years were permanently or temporarily employed in 2015 (Statistics Bureau, Ministry of Inner Affairs and Communication of Japan 2016a). In addition, $62.4 \%$ of babies born in 2015 were to women in this age group (Ministry of Health, Labour and Welfare 2016a).

Infectious diseases can cause sudden illness in infants and toddlers. The 2014 Patient Survey (Ministry of Health, Labour and Welfare 2015) indicated that children in Japan averaged two visits per month to medical facilities because of diseases and injuries. The Infection Control Guideline for Nurseries (Ministry of Health, Labour and Welfare 2012 , 2018) instructs general nursery schools to refrain from accepting infants and toddlers with mild fevers (37.538.0 centigrade) who are not doing well. However, it is difficult for nursery schools to judge precisely whether or not these children are in good condition, and it is probable that most nursery schools simply do not accept children with temperatures above 37.5 centigrade. Therefore, working parents who have children with even mild illnesses must seek alternative day-care service providers. Alternative providers may include relatives and friends, but these options are not always available. In such cases, one of the working parents - usually the mother in Japan (Cabinet Office, Government of Japan 2017) — must be absent from their workplace to care for the child.

The Japanese Government has attempted to increase the capacity of day-care services for children in an unhealthy condition (Council for Gender Equality of Cabinet Office, Government of Japan 2013). A previous report (Ehara 2017) analyzed the straight distance to nurseries for children with mild acute illness (787 nurseries) from each residential block in Japan (median size of $0.18 \mathrm{~km}^{2}$ ). That study showed that $47.0 \%$ of children in Japan lived within $3 \mathrm{~km}$ of the nearest nursery, $64.8 \%$ within $5 \mathrm{~km}$, and $82.1 \%$ within $10 \mathrm{~km}$. However, most roads do not follow straight lines because of geographical features such as rivers and mountains. This means the actual travel time is likely to affect practical access to nurseries that accept children with mild acute illness.

Received April 5, 2018; revised and accepted June 25, 2018. Published online July 6, 2018; doi: 10.1620/tjem.245.153.

Corresponence: Akira Ehara, M.D., Ph.D., Faculty of Health Services Management, Hiroshima International University, 1-5 Noboricho, Naka-ku, Hiroshima, Hiroshima 730-0016, Japan.

e-mail: a-ehara@hw.hirokoku-u.ac.jp 
A recent survey conducted in the Kanto region (Yamazaki et al. 2017) indicated that $60.6 \%$ of parents sometimes used their automobile or public transport (e.g., a taxi) to transport children to childcare facilities. In most prefectures in Japan, the average number of automobiles exceeds one per household (excluding the five overpopulated areas: Tokyo, Kanagawa, Kyoto, Osaka, and Hyogo) (Automobile Inspection \& Registration Information Association 2015). Therefore, to clarify practical access to nurseries for children with mild acute illnesses, this study used geographic information systems (GIS) to calculate the driving time necessary for parents to transport their children from each residential area to the nearest nursery for children with mild acute illness. Calculations were based on the algorithm widely used in car navigation systems.

\section{Methods}

The list of 787 subsidized nurseries that accept children with mild acute illness in Japan provided by the Ministry of Health, Labour and Welfare (as of March 31, 2016) was used for this study. This list was also used in the previous study (Ehara 2017). The present author divided Japan into 219,100 residential blocks (median area: $0.17 \mathrm{~km}^{2}$ ) and the child population into three groups (aged $0-4$, 5-9, and 10-14 years), consistent with the 2015 Population Census (Statistics Bureau, Ministry of Internal Affairs and Communications of Japan 2017). As $82.7 \%$ of children who used nurseries for children with acute illness in the 2012 fiscal year were aged under 5 years (Council for Gender Equality of Cabinet Office, Government of Japan 2013), this analysis focused on driving time to the nearest qualifying nursery from each residential block in which children aged 0-4 years lived.

A GIS using ArcGIS version 10.5.1 software (Esri, Redlands,
CA, USA) was used to determine the latitude and longitude of all residential blocks in Japan (Statistics Bureau, Ministry of Internal Affairs and Communications of Japan 2017). The geocoding service for CSV-formatted files on the Internet, provided by the Center for Spatial Information Science of The University of Tokyo (Center for Spatial Information Science, The University of Tokyo 2015) was used to determine the coordinates for each nursery for children with mild acute illness. GIS using ArcOnline (January 24-26, 2017) was used to identify residential blocks that could reach the nearest nursery for children with mild acute illness within 15 or 30 minutes by automobile. This system estimates travel time using Dijkstra's algorithm (Dijkstra 1959), which is widely used in car navigation systems. The mean automobile velocity as a function of the type and width of roads according to road density was pre-fixed in ArcOnline, based on the 2010 Road Traffic Census (Ministry of Land, Infrastructure, Transport and Tourism 2011) (Table 1). In addition, GIS using ArcGIS version 10.5.1 was used to identify residential blocks within a straight distance of $10 \mathrm{~km}$ of such nurseries by spherical trigonometry (Todhunter 2013).

In 2015, Japan's population density was 341 persons $/ \mathrm{km}^{2}$ (Table 2; Statistics Bureau, Ministry of Internal Affairs and Communications of Japan 2016b). Population density was high in Kanto (1,333 persons $/ \mathrm{km}^{2}$ ), Chubu (353 persons $\left./ \mathrm{km}^{2}\right)$, Kinki (765 persons $/ \mathrm{km}^{2}$ ), and Kyushu and Okinawa (345 persons $/ \mathrm{km}^{2}$ ). Population density was low in Hokkaido (69 persons $/ \mathrm{km}^{2}$ ), Tohoku (141 persons $\left./ \mathrm{km}^{2}\right)$, Chugoku (234 persons $/ \mathrm{km}^{2}$ ), and Shikoku (205 persons $/ \mathrm{km}^{2}$ ). The mean number of household members in 2015 ranged from 2.24 in Hokkaido to 2.67 in Tohoku (Table 2). The employment rate for women aged 25-34 years in 2015 (Statistics Bureau, Ministry of Internal Affairs and Communications of Japan 2016a) ranged from $69.0 \%$ in Kinki to $75.9 \%$ in Tohoku (Table 3 ). The proportion of healthy nursery users, which was approximated by dividing nursery users by the child population aged $0-5$ years, ranged from $28.5 \%$ in Hokkaido to $43.8 \%$ in

Table 1 . Mean velocity of an automobile according to the type and width of roads $(\mathrm{km} / \mathrm{h})$.

\begin{tabular}{|c|c|c|c|c|c|c|}
\hline \multirow{2}{*}{$\begin{array}{c}\text { Location } \\
\text { (Road density) }\end{array}$} & \multirow{2}{*}{ Road type } & \multicolumn{5}{|c|}{ Width (m) } \\
\hline & & $\geq 13$ & $5.5-13$ & $3-5.5$ & $<3$ & Unknown \\
\hline \multirow{7}{*}{$\begin{array}{c}\text { Urban } \\
\left(\geq 15,000 \mathrm{~m} / \mathrm{km}^{2}\right)\end{array}$} & Highway & & & & & \\
\hline & \multirow{3}{*}{ Main road $\quad \begin{array}{r}\text { Inter-city } \\
\text { Intra-city }\end{array}$} & 80 & 80 & 50 & 10 & 2 \\
\hline & & 60 & 60 & 50 & 10 & 2 \\
\hline & & & & & & \\
\hline & National & 30 & 20 & 17 & 7 & 2 \\
\hline & Prefectural and municipal & 30 & 17 & 17 & 7 & 2 \\
\hline & Other roads and unknown & 30 & 12 & 8 & 4 & 2 \\
\hline \multirow{7}{*}{$\begin{array}{c}\text { Rural I } \\
(5,000-15,000 \\
\left.\mathrm{m} / \mathrm{km}^{2}\right)\end{array}$} & Highway & & & & & \\
\hline & Inter-city & 80 & 80 & 60 & 15 & 10 \\
\hline & Intra-city & 60 & 60 & 60 & 15 & 10 \\
\hline & Main road & & & & & \\
\hline & National & 50 & 40 & 25 & 10 & 10 \\
\hline & Prefectural and municipal & 50 & 35 & 25 & 10 & 10 \\
\hline & Other road and unknown & 50 & 20 & 15 & 10 & 10 \\
\hline \multirow{7}{*}{$\begin{array}{c}\text { Rural II } \\
\left(<5,000 \mathrm{~m} / \mathrm{km}^{2}\right)\end{array}$} & Highway & & & & & \\
\hline & Inter-city & 80 & 80 & 60 & 15 & 10 \\
\hline & Intra-city & 60 & 60 & 60 & 15 & 10 \\
\hline & Main road & & & & & \\
\hline & National & 55 & 50 & 30 & 10 & 10 \\
\hline & Prefectural and municipal & 55 & 45 & 30 & 10 & 10 \\
\hline & Other road and unknown & 55 & 30 & 15 & 10 & 10 \\
\hline
\end{tabular}

Mean automobile velocity, as a function of the type and width of roads according to road density, was based on the 2010 road traffic census (Ministry of Land, Infrastructure, Transport and Tourism 2011).

Geographical information systems using ArcOnline was used to estimate travel time using Dijkstra's (1959) algorithm, which is widely used in car navigation systems. 
Table 2. Social indicators for eight Japanese regions (2015).

\begin{tabular}{|c|c|c|c|c|c|c|c|}
\hline \multirow[t]{2}{*}{ Region } & \multicolumn{2}{|c|}{ (a) Total population } & \multicolumn{2}{|c|}{ Total land area $^{\mathrm{a}}$} & \multicolumn{3}{|c|}{ Population density (b) Total households (a)/(b) Household members } \\
\hline & (person) & $(\%)$ & $\left(\mathrm{km}^{2}\right)$ & $(\%)$ & (persons $/ \mathrm{km}^{2}$ ) & & (persons) \\
\hline A Hokkaido & $5,384,000$ & 4.2 & 78,421 & 21.0 & 69 & $2,404,800$ & 2.24 \\
\hline B Tohoku & $8,983,000$ & 7.1 & 63,852 & 17.1 & 141 & $3,362,000$ & 2.67 \\
\hline C Kanto & $42,992,000$ & 33.8 & 32,240 & 8.6 & 1,333 & $18,514,600$ & 2.32 \\
\hline D Chubu & $23,282,000$ & 18.3 & 66,048 & 17.7 & 353 & $8,757,600$ & 2.66 \\
\hline E Kinki & $20,728,000$ & 16.3 & 27,101 & 7.3 & 765 & $8,599,600$ & 2.41 \\
\hline F Chugoku & $7,440,000$ & 5.9 & 31,818 & 8.5 & 234 & $2,965,000$ & 2.51 \\
\hline G Shikoku & $3,847,000$ & 3.0 & 18,789 & 5.0 & 205 & $1,567,500$ & 2.45 \\
\hline H Kyushu and Okinawa & $14,455,000$ & 11.4 & 41,918 & 11.2 & 345 & $5,844,400$ & 2.47 \\
\hline Total $^{\mathrm{a}}$ & $127,111,000$ & 100.0 & 372,969 & 100.0 & 341 & $52,015,500$ & 2.44 \\
\hline
\end{tabular}

aTotal land area excludes the northern territories and Takeshima island.

Table 3. Social indicators for workforce and nursery use.

\begin{tabular}{|c|c|c|c|c|c|}
\hline \multirow[t]{2}{*}{ Region } & \multicolumn{2}{|c|}{$\begin{array}{c}\text { Employment rate }(\%) \\
25-34 \text { years }(2015)\end{array}$} & \multirow{2}{*}{$\begin{array}{l}\text { (c) Population } 0-5 \text { years } \\
\text { (2015) }\end{array}$} & \multirow{2}{*}{$\begin{array}{c}\text { (d) No. nursery users } \\
\text { (2015) }\end{array}$} & \multirow{2}{*}{$\begin{array}{l}(\mathrm{d}) /(\mathrm{c}) \text { Proportion of } \\
\text { nursery users }(\%)\end{array}$} \\
\hline & Male & Female & & & \\
\hline A Hokkaido & 88.9 & 70.6 & 225,760 & 64,365 & 28.5 \\
\hline B Tohoku & 90.4 & 75.9 & 381,346 & 142,531 & 37.4 \\
\hline C Kanto & 90.1 & 73.0 & $2,012,941$ & 627,259 & 31.2 \\
\hline D Chubu ${ }^{a}$ & 92.9 & 70.9 & $1,134,050$ & 462,099 & 40.7 \\
\hline E Kinki & 87.8 & 69.0 & 977,070 & 312,825 & 32.0 \\
\hline F Chugoku & 90.9 & 71.9 & 362,217 & 155,838 & 43.0 \\
\hline G Shikoku & 88.1 & 75.4 & 170,922 & 74,797 & 43.8 \\
\hline H Kyushu and Okinawa & 90.4 & 72.4 & 767,369 & 325,889 & 42.5 \\
\hline Total & 90.0 & 72.1 & $6,031,675$ & $2,165,603$ & 35.9 \\
\hline
\end{tabular}

aEmployment rates of Nagano and Yamanashi in Chubu were analyzed as in Kanto region.

bUsers of general nursery schools.

Shikoku (Table 3; Ministry of Health, Labour and Welfare 2016b; Statistics Bureau, Ministry of Internal Affairs and Communications of Japan 2017).

This study did not require ethical approval from the Medical Research Ethics Committee of Hiroshima International University because only previously published Japanese government data were used.

\section{Results}

Of the 4,987,706 children aged younger than 5 years as of $2015,51.7 \%$ lived in areas from which the nearest nursery that accepted children with mild acute illness was accessible by automobile within 0-15 minutes (Table 4). These areas represented $4.2 \%$ of Japan's total land area (Table 4 and Fig. 1). The proportion of children who could access such nurseries was high in over-populated regions such as Kanto $(56.9 \%)$ and Kinki $(63.7 \%)$, but low in under-populated regions such as Hokkaido $(9.1 \%)$ and Tohoku (29.3\%).

Areas from which qualifying nurseries were accessible within $0-30$ minutes represented $14.6 \%$ of Japan's total land area, with $81.5 \%$ of Japan's children living in these areas. The same percentage of children (81.5\%) lived within 10 $\mathrm{km}$ of such nurseries (Table 4 and Fig. 1). The percentage of children with mild acute illness who could access a nursery within 0-30 minutes by automobile was highest in Kinki $(89.8 \%)$ and lowest in Hokkaido (35.9\%). The percentages of children living within a straight distance of $10 \mathrm{~km}$ of such nurseries showed similar results (Kinki: 91.1\%, Hokkaido: 20.7\%).

\section{Discussion}

In a potential over-adaptation of Japan's Infection Control Guideline for Nursery (Ministry of Health, Labour and Welfare 2012, 2018), most nursery schools in Japan do not accept children with even mild illnesses. This is intended to prevent the spread of infectious diseases. If alternative day-care services are not readily available for children with sudden-onset acute illness, one parent-usually the mother (Cabinet Office, Government of Japan 2017) - may have to take leave from work to care for the child. For working parents in other countries, day-care arrangements for a child with mild acute illness may present a similar problem. An earlier study reported that a primary cause of worker absence in Europe was sudden-onset infectious diseases of children (Peetoom et al. 2018).

Many parents sometimes use their automobile or public transport (e.g., a taxi) to transport children to childcare facilities (Yamazaki et al. 2017). In addition, the average number of automobiles across Japan generally exceeds one per household (excluding over-populated areas) (Automobile Inspection \& Registration Information Association 2015). Therefore, to investigate practical access to the nearest nurseries for children with acute illness, I calculated the actual driving time from each residential block. These calculations were based on the car navigation algorithm 
Table 4. Percentages of child population and land area accessible to nurseries for children with acute mild illness calculated using driving time and straight distance.

\begin{tabular}{|c|c|c|c|c|c|}
\hline \multirow{2}{*}{\multicolumn{2}{|c|}{ Region }} & & \multicolumn{2}{|c|}{ Automobile } & \multirow{2}{*}{ Linear distance $<10 \mathrm{~km}(\%)$} \\
\hline & & & $0-15 \min (\%)$ & $0-30 \min (\%)$ & \\
\hline \multirow[t]{2}{*}{ A } & Hokkaido & Child population & 9.1 & 35.9 & 20.7 \\
\hline & & Area & 0.2 & 1.6 & 1.5 \\
\hline \multirow[t]{2}{*}{ B } & Tohoku & Child population & 29.3 & 59.6 & 56.5 \\
\hline & & Area & 1.8 & 8.1 & 8.9 \\
\hline \multirow[t]{2}{*}{$\mathrm{C}$} & Kanto & Child population & 56.9 & 89.6 & 89.0 \\
\hline & & Area & 11.0 & 37.2 & 34.7 \\
\hline \multirow[t]{2}{*}{ D } & Chubu & Child population & 44.2 & 79.8 & 79.1 \\
\hline & & Area & 5.6 & 17.6 & 22.2 \\
\hline \multirow[t]{2}{*}{$\mathrm{E}$} & Kinki & Child population & 63.7 & 89.8 & 91.1 \\
\hline & & Area & 7.7 & 22.7 & 27.5 \\
\hline \multirow[t]{2}{*}{$\mathrm{F}$} & Chugoku & Child population & 53.2 & 81.9 & 85.5 \\
\hline & & Area & 4.0 & 18.5 & 23.7 \\
\hline \multirow[t]{2}{*}{ G } & Shikoku & Child population & 51.7 & 72.5 & 80.7 \\
\hline & & Area & 4.3 & 12.3 & 19.0 \\
\hline \multirow[t]{2}{*}{$\mathrm{H}$} & Kyushu and Okinawa & Child population & 56.6 & 78.6 & 81.8 \\
\hline & & Area & 6.0 & 20.6 & 26.8 \\
\hline & Total & Child population & 51.7 & 81.5 & 81.5 \\
\hline & & Area & 4.2 & 14.6 & 17.2 \\
\hline & Highest & Child population & 63.7 (Kinki) & 89.8 (Kinki) & 91.1 (Kinki) \\
\hline & & Area & 11.0 (Kanto) & 37.2 (Kanto) & 34.7 (Kanto) \\
\hline & Lowest & Child population & 9.1 (Hokkaido) & 35.9 (Hokkaido) & 20.7 (Hokkaido) \\
\hline & & Area & 0.2 (Hokkaido) & 1.6 (Hokkaido) & 1.5 (Hokkaido) \\
\hline
\end{tabular}

Travel time was calculated using Dijkstra's (1959) algorithm, which is widely used in car navigation systems, and linear distance was calculated by spherical trigonometry (Todhunter 2013).

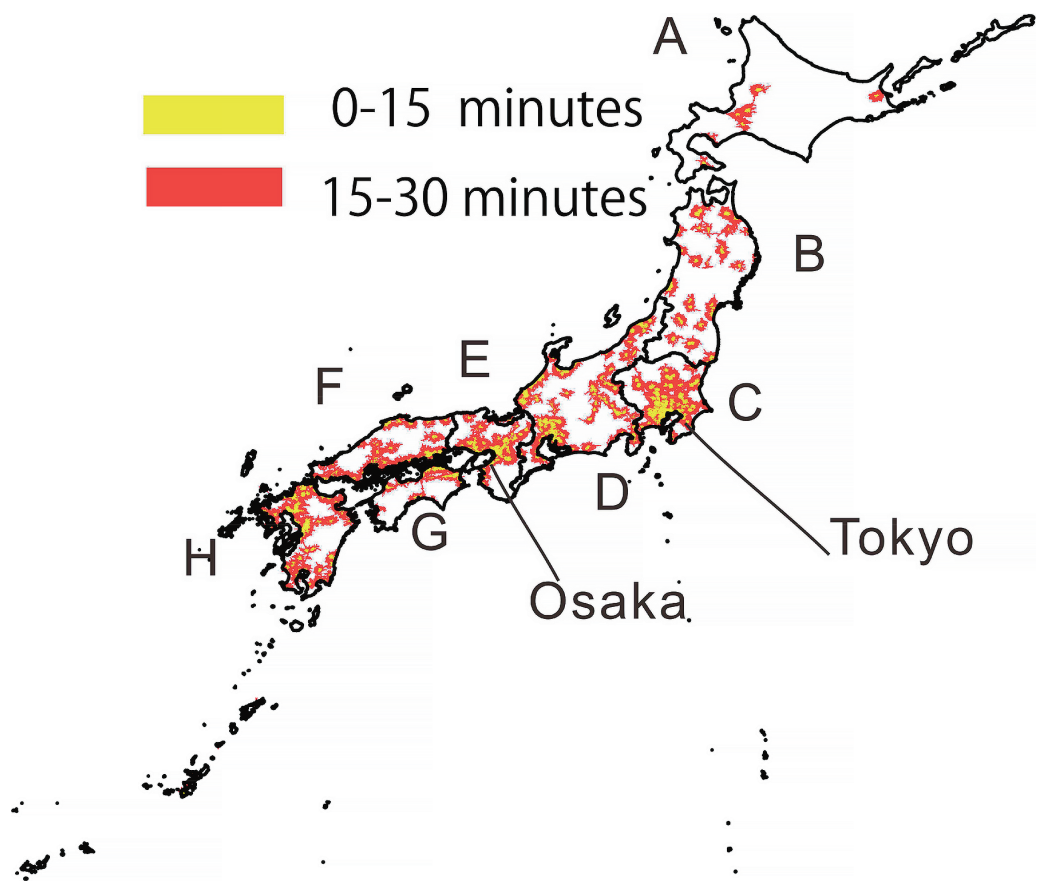

Fig. 1. Travel time to the nearest nursery for children with mild acute illness.

Areas accessible by automobile are shown in yellow (0-15 minutes) and red (15-30 minutes). The territory of Japan is divided into eight regions: A, Hokkaido; B, Tohoku; C, Kanto; D, Chubu; E, Kinki; F, Chugoku; G, Shikoku; H, Kyushu and Okinawa. Kanto (C), Kinki (E), Chubu (D), and Kyushu and Okinawa (H) have high population densities. Other regions have lower population densities. Map of Japan reprinted from Global Map Japan (public domain, open-access resources) under a CC BY license, with permission from the Geospatial Information Authority of Japan.

using data for the mean velocity of an automobile by type and width of roads in urban and rural areas. This showed that $51.7 \%$ of children in Japan could access the nearest nursery for children with acute illness by automobile within $0-15$ minutes, and $81.5 \%$ within $0-30$ minutes. This study also calculated the linear distance from each residential 
block to the nearest nursery for children with mild acute illness, using data from the 2015 Population Census, finding that $81.5 \%$ of Japanese children aged $0-4$ years lived within $10 \mathrm{~km}$ of these nurseries. This percentage $(81.5 \%)$ was comparable to the result $(82.1 \%)$ calculated using data from the 2010 Population Census (Ehara 2017). Both calculation methods (travel time and linear distance) showed interregional differences in accessibility, and a higher proportion of children had access to these nurseries in heavily populated regions (e.g., Kanto and Kinki), compared with less populated regions (e.g., Hokkaido and Tohoku).

Japan faces a problem of the combined effects of aging and a decreasing birth rate, which predicts a decrease in the labor force in the near future. Increasing the workforce requires supporting working parents, especially mothers, who are raising children. Since 1994, the Japanese government has subsidized nurseries for children in an unhealthy condition (Ministry of Health, Labour and Welfare 2009). However, a higher proportion of parents who live in northern parts of Japan (e.g., Hokkaido and Tohoku) cannot transport their children to nurseries for children with mild acute illness within 15 or 30 minutes compared with those in other regions because there are few such nurseries nearby.

The employment rates of women aged 25-34 years in Hokkaido (70.6\%) and Tohoku (75.9\%) were comparable with those in Kanto (73.0\%) and Kinki (69.0\%) (Table 3). In addition, nursery users per population aged $0-5$ years in Hokkaido (28.5\%) and Tohoku (37.4\%) did not differ markedly from those in Kanto (31.2\%) and Kinki (32.0\%) (Table 3 ). There were no significant differences in average numbers of household members between under-populated regions such as Hokkaido (2.24) and Tohoku (2.67), and over-populated areas such as Kanto (2.32) and Kinki (2.41) (Table 2). Given the provision of national subsidies and lack of major differences in official indicators concerning the childcare environment, children and parents throughout Japan should have equal access to these services.

The 2014 Patient Survey (Ministry of Health, Labour and Welfare 2015) reported that children in Japan visited medical facilities because of diseases and injuries an average of twice a month. This highlights that support for working parents requires provision of nursery services for children with mild acute illness, as well as for healthy children. Quantitative data analysis based on GIS is indispensable for promoting discussion regarding the distribution and accessibility of such nurseries.

There are limitations in the present study, as listed below.

1) Other potential providers of childcare (e.g., relatives) were not considered in this study, although childrearing families may live close to such relatives, particularly in rural areas.

2) Operating hours of nurseries were not considered.

3) Only pre-fixed data for average automobile velocity were used, and the effects of factors such as traffic conges- tion and poor weather were not considered.

4) It was unknown whether every nursery claiming to accept children aged 0-4 years was able to care for babies aged 3 months or younger that might need a greater level of care.

5) It was unknown whether every nursery could manage all types of illnesses.

6) The socioeconomic status of parents in each residential block was unknown.

7) Only nurseries for children with mild acute illness subsidized by the Japanese government were analyzed. Non-subsidized facilities were not included.

In conclusion, $51.7 \%$ of children younger than 5 years lived in areas from which the nearest nursery for children with mild acute illness was accessible within 0-15 minutes by automobile. Furthermore, $81.5 \%$ lived within $0-30 \mathrm{~min}-$ utes of such nurseries, and the same percentage $(81.5 \%)$ lived within a linear distance of $10 \mathrm{~km}$ of such nurseries. Both calculation methods (travel time and linear distance) showed inter-regional differences in accessibility, and a higher proportion of children in heavily populated regions (e.g., Kanto and Kinki) could access these nurseries, compared with less populated regions (e.g., Hokkaido and Tohoku). Children and caregivers throughout Japan should have equal access to these nurseries, because the national government subsidizes such services.

\section{Acknowledgments}

I thank Audrey Holmes, MA, from Edanz Group (http:// www.edanzediting.com/ac) for editing a draft of this manuscript.

This research was supported by the Hiroshima International University research fund.

This study was supported by Joint Research Program No. 808 at CSIS, The University of Tokyo (Geocoding service for CSV formatted file on the World Wide Web).

\section{Conflict of Interest}

The author declares no conflict of interest.

\section{References}

Automobile Inspection \& Registration Information Association (2015) Car Ownership Rate in Each Prefecture. https://www.airia.or.jp/publish/statistics/trend.html [Accessed: June 10, 2018] (in Japanese).

Cabinet Office, Government of Japan (2017) Declining Birthrate White Paper, FY2016.

http://www8.cao.go.jp/shoushi/shoushika/whitepaper/ measures/w-2017/29webhonpen/index.html [Accessed: June 10, 2018] (in Japanese).

Center for Spatial Information Science, The University of Tokyo (2015) Geocoding service for CSV formatted file on WWW. http://newspat.csis.u-tokyo.ac.jp/geocode-cgi/geocode. cgi?action=start [Accessed: October 31, 2017] (in Japanese).

Council for Gender Equality of Cabinet Office, Government of Japan (2013) About day-care for sick children, the 8th conference of child and child-feeding support, November 25. http://www8.cao.go.jp/shoushi/shinseido/meeting/kodomo_ kosodate/b_8/pdf/s2-2.pdf 
[Accessed: June 10, 2018] (in Japanese).

Dijkstra, E.W. (1959) A note on two problems in connexion with graphs. Numerische Mathematik, 1, 269-271.

Ehara, A. (2017) Unequal accessibility of nurseries for sick children in over- and under-populated areas of Japan. Tohoku J. Exp. Med., 241, 97-102.

Ministry of Health, Labour and Welfare (2009) The 27th Falling Birthrate Special Committee of Social Security Council, September 30. http://www.mhlw.go.jp/shingi/2009/09/dl/s0930-9d.pdf [Accessed: June 10, 2018] (in Japanese).

Ministry of Health, Labour and Welfare (2012) Infection Control Guideline for Nursery, 2012.

http://www.mhlw.go.jp/bunya/kodomo/pdf/hoiku02.pdf [Accessed: June 10, 2018] (in Japanese).

Ministry of Health, Labour and Welfare (2015) Patient Survey, 2014.

http://www.e-stat.go.jp/SG1/estat/NewList.do?tid=000001031167 [Accessed: June 10, 2018] (in Japanese).

Ministry of Health, Labour and Welfare (2016a) Vital Statistics, 2015.

http://www.e-stat.go.jp/SG1/estat/NewList.do?tid=000001028897 [Accessed: June 10, 2018] (in Japanese).

Ministry of Health, Labour and Welfare (2016b) Report on Social Welfare Administration and Services, 2015.

https://www.e-stat.go.jp/stat-search/files?page=1\&layout=data list \& tstat $=000001034573 \&$ cycle $=8 \&$ tclass $1=000001091575 \&$ tclass $2=000001091616 \&$ second $2=1$

[Accessed: June 10, 2018] (in Japanese).

Ministry of Health, Labour and Welfare (2018) Infection Control Guideline for Nursery, 2018.

http://www.mhlw.go.jp/file/06-Seisakujouhou-11900000-Koy oukintoujidoukateikyoku/0000201596.pdf

[Accessed: June 10, 2018] (in Japanese).

Ministry of Land, Infrastructure, Transport and Tourism (2011) Road Traffic Census, 2010. http://www.mlit.go.jp/road/census/h22-1/

[Accessed: June 10, 2018] (in Japanese).

Peetoom, K.K.B., Crutzen, R., Bohnen, J.M.H.A., Verhoeven, R., Nelissen-Vrancken, H.J.M.G., Winkens, B., Dinant, G.J. \& Cals, J.W.L. (2018) Optimising decision making on illness absenteeism due to fever and common infections within childcare centres: development of a multicomponent intervention and study protocol of a cluster randomised controlled trial. BMC Public Health, 18, 61.

Statistics Bureau, Ministry of Internal Affairs and Communications of Japan (2016a) 2015 Yearly Average Results of Labour Force Survey.

http://www.stat.go.jp/english/data/roudou/results/annual/ft/ index.html

[Accessed: June 10, 2018].

Statistics Bureau, Ministry of Internal Affairs and Communications of Japan (2016b) Japan Statistical Yearbook 2017, Ministry of Internal Affairs and Communications of Japan, Tokyo. http://www.stat.go.jp/data/nenkan/66nenkan/index.html [Accessed: June 10, 2018] (in Japanese).

Statistics Bureau, Ministry of Internal Affairs and Communications of Japan (2017) 2015 Population Census.

https://www.e-stat.go.jp/stat-search/database?page $=1 \&$ layout $=$ normal\& toukei $=00200521 \&$ tstat $=000001080615 \&$ survey $=\%$ E5\%9B\%BD $\%$ E5\%8B $\%$ A2\%E8\%AA\%BF\%E6\%9F\%BB\&r esult_page $=1 \&$ second $=1$ [Accessed: June 10, 2018] (in Japanese).

Todhunter, I. (2013) Spherical Trigonometry, For the Use of Colleges and Schools, With Numerous Examples, 3rd ed., Kindle version, Research Press, Champaign, IL.

Yamazaki, S., Kaneko, T., Mizuno, M. \& Nakayama, H. (2017) An examination of the relationships between the method of going to a childcare facility and children awareness in that setting. Bulletin of Tokyo University and Graduate School of Social Welfare, 8, 43-54 (in Japanese). 